Grand Valley State University

ScholarWorks@GVSU

$11-2001$

\title{
Media Images and Women's Self-Evaluations: Social Context and Importance of Attractiveness as Moderators
}

\author{
Donna Henderson-King \\ Grand Valley State University, hendersd@gvsu.edu \\ Eaaron Henderson-King \\ Grand Valley State University, henderse@gvsu.edu \\ Lisa Hoffmann \\ U.S. Department of Labor
}

Follow this and additional works at: https://scholarworks.gvsu.edu/psy_articles

Part of the Psychology Commons

\section{ScholarWorks Citation}

Henderson-King, Donna; Henderson-King, Eaaron; and Hoffmann, Lisa, "Media Images and Women's SelfEvaluations: Social Context and Importance of Attractiveness as Moderators" (2001). Peer Reviewed Articles. 30.

https://scholarworks.gvsu.edu/psy_articles/30

This Article is brought to you for free and open access by the Psychology Department at ScholarWorks@GVSU. It has been accepted for inclusion in Peer Reviewed Articles by an authorized administrator of ScholarWorks@GVSU. For more information, please contact scholarworks@gvsu.edu. 


\section{Media Images and Women's Self-Evaluations: Social Context and Importance of Attractiveness as Moderators}

\author{
Donna Henderson-King \\ Eaaron Henderson-King \\ Grand Valley State University \\ Lisa Hoffmann \\ U.S. Department of Labor
}

1994) and eating pathology (Stice, Schupak-Nueberg, Shawn, \& Stein, 1994). Very little research has examined the moderating effects of individual difference factors, and almost no empirical research has examined the effects of the social context on exposure to media images. In this article, we examine the psychological effects that media imagery can have on women's selfperceptions, particularly those concerning physical attractiveness. Most important, we consider the social context in which such images are viewed and the moderating influence of the importance women place on attractiveness.

\section{Media Influences on Women's Self-Evaluations}

An expanding critique of contemporary media points to the pervasiveness of idealized depictions of female attractiveness, which are difficult, if not impossible, for most women to attain, and asserts that a psychological toll is taken by exposure to such images (e.g., Adams \& Crossman, 1978; Faludi, 1991; Fredrickson \& Roberts, 1997; Itzin, 1986; Kilbourne, 1987; Silverstein, Perdue, Peterson, \& Kelly, 1986; Wolf, 1991). The pervasiveness of such imagery, and the ongoing experience of failure to meet the unrealistic expectations established by these

Authors' Note: The authors wish to thank their research assistants for all of their help in conducting these studies. We would especially like to acknowledge the contributions of Michelle Cruz, who was very instrumental in running Study 2. Correspondence concerning this article should be addressed to the first or second author at Department of Psychology, Grand Valley State University, Allendale, MI 49401; e-mail: hendersd@gvsu.edu or henderse@gvsu.edu.

PSPB, Vol. 27 No. 11, November 2001 1407-1416

(C) 2001 by the Society for Personality and Social Psychology, Inc. 
images, it is argued, result in increased concern with physical attractiveness among women and diminished self-confidence and self-esteem. In particular, there is growing awareness of the potential mental and physical health implications of cultural pressures for women to be thin (Garner, Garfinkel, Schwartz, \& Thompson, 1980; Silverstein et al., 1986). Others have found that exposure to photographs of attractive others can result in lowered self-ratings of attractiveness (Brown, Novick, Lord, \& Richards, 1992; Cash, Cash, \& Butters, 1983), more negative mood states (Stice \& Shaw, 1994), and diminished satisfaction with one's physical attractiveness (Richins, 1991).

However, there is also evidence that the impact of viewing ideal images may not be uniformly or consistently negative (Brown et al., 1992; Henderson-King \& Henderson-King, 1997; Stice \& Shaw, 1994). For example, Richins (1991) found that viewing ideal images negatively affected women's satisfaction with their physical attractiveness but not ratings of their own attractiveness. Moreover, Myers and Biocca (1992) found that viewing ideal images led to less body-size overestimation and more positive mood states. Henderson-King and Henderson-King (1997) showed that individual differences in body weight moderate women's vulnerability to the negative impact of media images; heavier women felt worse about their bodies after viewing ideal images from popular magazines. They also found that responses to these images were a function of self-monitoring; exposure had fewer negative effects on high self-monitors.

\section{Effects of the Social Context}

The importance of the social context in influencing the self-concept has been well recognized in both the sociological (Cooley, 1902; Mead, 1934; Schafer \& Keith, 1985) and the social psychological literature (Hardin \& Higgins, 1996; Markus \& Nurius, 1986; McGuire \& Padawer-Singer, 1976). While physical attractiveness norms are transmitted through media images, these norms are also communicated through both direct and indirect social interactions. Evaluative comments and conversations (in which we engage or that we overhear) provide sources of information about social expectations, and little attention has been given to how these forms of communication affect women's self-evaluations and, further, how they might moderate the relationship between viewing ideal images and self-evaluations.

Research examining reflected self-appraisals has shown that self-evaluations are influenced by our beliefs about how others view us (Felson, 1993). Although much of this research has focused on the effects of dyadic appraisals on self-perceptions (i.e., the effect of A's appraisal of B on B's self-perceptions), it also seems reasonable to expect that awareness of third-party appraisals could influence self-perceptions (i.e., awareness of A's appraisal of B could influence C's selfperceptions). A judgmental comment, regardless of the target, communicates and makes salient the values and standards within a given social context. Consequently, a listener, even if they are not the target of such a comment, may use the communicated standard in making self-evaluations. In fact, it has been argued that the effects of reflected appraisals are primarily driven by people's beliefs about group norms and attitudes rather than simply the reflected appraisal of an individual (Felson, 1993; Kenny \& Albright, 1987). Similar arguments have been made by researchers examining socially shared cognitions (see Hinsz, Tindale, \& Vollrath, 1997; J. M. Levine, Resnick, \& Higgins, 1993).

Understanding how people adapt to pervasive social stimuli provides a window into what might occur when women encounter ideal imagery in varying social contexts. As stated above, idealized images of women are both homogeneous and pervasive in Western society. Because of their prevalence, these images are likely to be automatically, perhaps nonconsciously, processed. A substantial body of research examining automaticity in information processing has shown that the automatic processing of stimuli influences both social and nonsocial judgments (e.g., Bargh \& Pietromonaco, 1982; Norman \& Shallice, 1986; Operario, Goodwin, \& Fiske, 1998; Perdue, Dovidio, Gurtman, \& Tyler, 1990). When a concept is regularly encountered and activated it becomes easier to subsequently activate and it is more likely to be processed inattentively (Bodenhausen \& Macrae, 1998; Devine, 1989; Dovidio \& Gaertner, 1993). Thus, given the pervasiveness of ideal media imagery, women may tend to nonconsciously process such stimuli and, therefore, be less likely to question social standards and expectations regarding attractiveness.

Researchers also have shown that conscious, or "controlled," processes (i.e., processes that require the perceiver to actively attend to stimuli) can override automatic processes (Bargh, 1982, 1990). For example, although people succumb to stereotype cues that are primed below conscious awareness, they are able to counter stereotypes when conscious of such cues (Devine, 1989; Higgins \& King, 1981). Thus, viewing ideal images within a context that elicits active attention may interrupt automatic processing and, therefore, increase the likelihood that a woman will question the images and associated social standards and/or her willingness to accept such standards (see Bodenhausen \& Macrae, 1998). In other words, when cues regarding attractiveness norms are relatively subtle, women may engage in nonconscious processing and thus be more likely to accept ideal images as a relevant point of comparison; however, when those cues are made more bla- 
tant through, for example, accompanying verbal commentary, women may engage in active processing and be more likely to question and resist cultural norms.

Furthermore, it also may be the case that strong, relatively explicit messages regarding social expectations and norms may elicit psychological reactance (Brehm \& Brehm, 1981). In particular, researchers have shown that threatening and unexpected events tend to lead to psychological reactance and to attempts to regain control of the situation (Brehm, 1966; Pittman \& D'Agostino, 1985). Thus, to the extent that women interpret messages regarding physical attractiveness as a proscription for their own behavior, they may react against the messages in an effort to defend their sense of personal freedom. Reactance should be especially strong if the messages are threatening to the self and if they are somewhat unexpected. Thus, the literatures on active processing and psychological reactance both suggest that women who are exposed to strong or arresting messages regarding attractiveness should be pressed to resist, or at least question, such messages' content.

\section{OVERVIEW AND HYPOTHESES: STUDY 1}

In Study 1, we examined whether viewing ideal images in a variety of social contexts affected women's self-evaluations. We exposed female undergraduate students to either neutral or ideal images of women from popular magazines. Social context was manipulated by having male confederates present in some sessions (a relatively subtle manipulation) but not others and by sometimes having them make evaluative remarks about several of the media images (a stronger manipulation). In the neutral image condition, because a concern with physical attractiveness was not being primed by the images, we expected that neither men's presence nor their comments about these images would have a significant effect on women's self-evaluations. In contrast, we expected that when viewing ideal media images of women, the mere presence of men should heighten the salience of physical attractiveness for many women, which should result in diminished self-evaluations. We further expected that hearing men's evaluative comments while viewing ideal images could lead to more conscious processing and/or psychological reactance on the part of women and that as a result, women in this condition should not report diminished self-evaluations.

\section{METHOD}

\section{Participants}

Female undergraduate students $(N=228)$ participated in this study as part of an introductory psychology course requirement. The average age of participants was
19. The majority of participants were White (60\%), $13 \%$ were Asian, $12 \%$ were Hispanic, 3\% were African American, $2 \%$ were Asian Indian, and $4 \%$ reported other or mixed racial identity. All participants were asked for their account of the purpose of the study. Six women suspected the true nature of the study; consequently, their data were dropped and analyses were based on the remaining 222 cases.

\section{Materials}

Images. In each condition, participants viewed a series of 40 slides of images (advertisements and layouts) from popular magazines. In the neutral condition, participants saw slides in which there were few human images; when human images were present, they were not in the foreground or they were idealized representations. Neutral slides focused primarily on products such as electronic equipment, furniture and household items, and vehicles. Images of food were avoided so as not to cue concerns with eating, dieting, or weight. In the ideal image condition, 10 slides used in the neutral condition were interspersed with 30 slides presenting ideal images of women. The latter slides contained images of female models that met the contemporary ideal of female attractiveness and focused primarily on products related to fashion, dieting, and cosmetics. ${ }^{1}$

Male presence. In the no men condition, no men were present during the sessions. In the men present condition, two male confederates simply acted as participants and sat in on the session. In the men comment condition, male confederates acted as participants and made brief evaluative comments in response to three slides. Identical comments were made in the neutral and ideal image conditions. To the 3 rd and 37 th slide, one confederate would comment, "Nice." To the 10th slide, the same male confederate would say, "Alright," at which point the second confederate would respond, "Yeah." All comments communicated positive evaluations of the images.

Dependent measures. Participants received a questionnaire that contained the Body-Esteem Scale (BES) (Franzoi \& Herzog, 1986; Franzoi \& Shields, 1984). The BES assesses the degree to which people are satisfied with various aspects of their bodies. Participants rate parts of the body using a scale ranging from 1 (strongly negative) to 5 (strongly positive). For women, these scores are then combined to form indices for three aspects of body-esteem: sexual attractiveness, physical condition, and weight concern. Higher scores are indicative of higher levels of esteem. The sexual attractiveness subscale is composed of items commonly believed to be associated with physical and sexual attractiveness (e.g., breasts and facial features). The weight concern subscale consists of body parts that are most influenced by weight 
gain or loss (e.g., hips, weight, waist). For the purpose of clarity, in this article, we refer to this variable as weightesteem, because a high score refers to more positive feelings. The physical condition subscale includes items such as physical stamina, reflexes, and health. Cronbach's alphas for physical condition, sexual attractiveness, and weight-esteem for the current sample were $.85, .83$, and .92 , respectively.

Participants also completed the State Self-Esteem Scale (SSES) (Heatherton \& Polivy, 1991), a 20-item inventory that measures momentary self-esteem. Heatherton and Polivy have reported evidence of good convergent and discriminant validity, as well as test-retest reliability. Participants rated each of the 20 items on a 5point scale anchored by 1 (not at all) and 5 (extremely). Cronbach's alpha for the current sample was .90 .

\section{Procedure}

Sessions were run with groups ranging in size from three to six women. At the beginning of each session, a female experimenter told the participants that the purpose of the study was to examine factors that make advertisements more likeable or memorable. Participants were told that they would view a series of 40 slides of magazine advertisements and that later in the session they would be asked to recall as many of the advertisements as possible. The experimenter explained that after viewing the slides, they would be asked to complete a filler task to keep them from rehearsing what they had seen. Participants then viewed the series of slides; the room was darkened and each slide was presented for approximately 4 seconds.

After viewing the slides, participants were reminded that the purpose of the filler task was to discourage rehearsal. They then completed the questionnaire containing the BES and SSES, ostensibly for another professor's study. They were then given 90 seconds to list as many of the advertisements as they could remember. After completing a final questionnaire about their participation in the study, they were fully debriefed.

\section{RESULTS}

A 2 (image: neutral vs. ideal) $\times 3$ (presence: no men vs. men present vs. men comment) multivariate analysis of variance (MANOVA) was conducted using the three subscales of the BES as dependent variables. The analysis yielded a marginally significant Image $\times$ Presence multivariate interaction, $F(6,430)=1.94, p=.07$. Univariate analyses revealed a significant Image $\times$ Presence interaction for the dependent variable of weightesteem, $F(2,216)=3.28, p<.05$. Simple effects analyses revealed that when exposed to the mere presence of men, participants exhibited higher weight-esteem in the neutral image condition $(M=3.10)$ than in the ideal image condition $(M=2.53), F(1,216)=8.07, p<.001$. In the no men condition, weight-esteem did not vary as a function of image $\left(M_{\text {Neutral }}=2.74\right.$ and $\left.M_{\text {Ideal }}=2.63\right)$. There was also no significant difference between the neutral and ideal image conditions when men commented $(M s=2.75$ and 3.03, respectively). Subsequent analyses also revealed that, in the ideal image condition, participants in the men comment condition expressed more positive weight-esteem $(M=3.03)$ than did participants in either the no men condition $(M=2.63)$ or the men present condition $(M=2.53 ; p \mathrm{~s}<.05)$. In the neutral image condition, there was no difference between groups as a function of social context.

A parallel 2 (image) $\times 3$ (presence) MANOVA was conducted using the SSES as a dependent variable. This analysis revealed no significant main effects or interactions.

\section{DISCUSSION}

These findings support our contention that the social context can moderate reactions to media images. Women who viewed ideal images reported lower levels of weight-esteem than did women who viewed neutral images, but this difference occurred only in the mere presence condition. Thus, viewing these images did produce the sort of negative effect that media critics have described, but only in a context in which men were part of the social environment. Moreover, it occurred only when men were silent; as predicted, men's evaluative comments had the effect of reversing the negative effect of men's mere presence. These results provide further evidence that exposure to ideal media images does not consistently result in negative psychological outcomes for women, and they illustrate how social contextual variables can moderate the influence of media images.

\section{STUDY 2}

The purpose of Study 2 was to replicate and extend the findings of Study 1 . We again considered the role of social context, but in Study 2, social ideals were conveyed by women rather than men. As in Study 1, women viewed either ideal or neutral images and either were or were not exposed to conversational cues regarding expectations about female attractiveness. In the neutral image condition, we predicted that women who were exposed to attractiveness cues would report lower self-evaluations, whereas women who were not exposed to such cues would not. In the ideal image condition, we predicted that women who were not exposed to attractiveness cues would report lower self-evaluations; however, we expected that women who also were exposed to attractiveness cues, and thus received a stronger, doublebarreled message, would not report lower self-evaluations. 
Study 2 also examined whether the importance women placed on attractiveness would moderate their reactions to ideal media images. A primary assumption of previous research is that exposure to ideal media images affects all women in the same manner, across all situations. This presupposes that women are equally and continually dissatisfied with their bodies and that physical attractiveness is an important dimension of the selfconcept for all women. People differ, however, in the importance they assign to different aspects of the self (Buunk, Collins, Taylor, VanYperen, \& Dakof, 1990; Collins, 1996; Taylor \& Lobel, 1989), and such differences may account for inconsistencies observed in women's responses to ideal media images (e.g., see HendersonKing \& Henderson-King, 1997). Women for whom attractiveness is important should be more likely to use media images as standards for comparison and will most likely fall short of such an unrealistic ideal. Thus, we predicted that women who see attractiveness as more important in their self-views would report more negative selfevaluations after exposure to ideal media images or to salient cues about attractiveness expectations.

\section{METHOD}

\section{Participants}

Participants were 117 undergraduate women who participated in the study as part of an introductory psychology course requirement. Characteristics of this sample were similar to those of Study $1 ; 68 \%$ of the participants were White, and the average age was 19. Data from 5 participants who expressed some suspicion of the actual purpose were excluded from the analyses.

\section{Procedure and Materials}

Participants were tested in groups of up to six individuals. On arrival, they were informed that because an earlier session was taking a little longer than had been expected, they would be given a preliminary questionnaire to complete while waiting for their session to begin. The preliminary questionnaire included numerous filler items and scales. Embedded within these items, participants were asked to rate how important physical attractiveness was to them using a scale ranging from 1 (unimportant) to 11 (important). They also assessed the degree to which being independent, sociable, creative, assertive, and athletic was to them. An importance of attractiveness score was created by obtaining a mean score for each participant across all traits except attractiveness and then subtracting this mean score from their score for attractiveness. Thus, positive scores reflect more importance placed on attractiveness, whereas negative scores indicate less importance placed on attractiveness.
TABLE 1: Means and Standard Deviations for Study 2 Variables

\begin{tabular}{lcc}
\hline Variable & $\mathrm{M}$ & $\mathrm{SD}$ \\
\hline Importance of attractiveness & -1.12 & 2.27 \\
BES subscales & & \\
$\quad$ Sexual attractiveness & 3.50 & .57 \\
$\quad$ Weight-esteem & 2.89 & .86 \\
Physical condition & 3.36 & .73 \\
SSES & 3.60 & .61 \\
Current feelings of attractiveness & 2.44 & 1.08 \\
\hline
\end{tabular}

NOTE $:$ BES = Body-Esteem Scale, SSES = State Self-Esteem Scale .

After completing the questionnaire, each group was brought to the lab. The experimenter explained that the study examined characteristics of advertisements that enhance their memorability. While participants completed consent forms, a confederate posing as an experimenter for another study entered the lab, addressed the experimenter by her name, and asked if she could borrow a pencil. The two then had a brief conversation about a fictional, mutual friend. In the neutral condition, this friend had to find a new apartment as a result of chronic roommate problems. In the appearance condition, the friend had become less attractive by "letting herself go" and gaining a lot of weight. Both conversations communicated an emotional tone of disappointment. Full scripts for the conversations are available upon request from the authors. ${ }^{2}$

After the confederate left the room, the rest of the session was similar to that of Study 1, except as follows: The participants viewed 15 rather than 40 images; in the ideal image condition, eight images were ideal and the remaining seven were neutral nonhuman images; after viewing the slides, participants completed a questionnaire packet that included the BES and SSES; a mood scale was included; and embedded in the series of mood items (e.g., interested, distressed) was the adjective attractive. Participants rated how much each descriptor applied to them using a 5 -point scale $(1=$ not at all, $5=$ extremely), and their rating for attractive was used as a measure of their current feelings of attractiveness.

\section{RESULTS}

We performed hierarchical regressions separately for each dependent variable (i.e., sexual attractiveness, weight-esteem, physical condition, SSES, and current feelings of attractiveness), entering image, conversation, and importance of attractiveness at Step 1, the two-way interactions at Step 2, and the three-way interaction at Step 3. Importance of attractiveness scores were centered and dummy codes $(0,1)$ were used for both image and conversation factors. Table 1 presents the means and standard deviations for each of the dependent vari- 
TABLE 2: Zero Order Correlations for All Study 2 Variables

\begin{tabular}{|c|c|c|c|c|c|c|c|c|}
\hline Variable & 1 & 2 & 3 & 4 & 5 & 6 & 7 & 8 \\
\hline 1. Images ${ }^{\mathrm{a}}$ & - & & & & & & & \\
\hline 2. Conversation ${ }^{\mathrm{b}}$ & -.05 & - & & & & & & \\
\hline 3. Importance of attractiveness & -.02 & .16 & - & & & & & \\
\hline 4. Sexual attractiveness (BES) & -.05 & .01 & .02 & - & & & & \\
\hline 5. Weight-esteem (BES) & -.10 & -.05 & .01 & .53 & - & & & \\
\hline 6. Physical condition (BES) & -.11 & .04 & .02 & .62 & .63 & - & & \\
\hline 7. SSES & -.13 & -.22 & -.16 & .44 & .51 & .40 & - & \\
\hline 8. Current attractiveness & -.14 & -.17 & .15 & .41 & .44 & .26 & .40 & - \\
\hline
\end{tabular}

NOTE: BES = Body-Esteem Scale, SSES = State Self-Esteem Scale.

a. Images were coded 0 for neutral and 1 for ideal.

b. Conversation was coded 0 for roommate and 1 for appearance.

ables as well as for the importance of attractiveness scale. Intercorrelations among all relevant variables are presented in Table 2.

There was a main effect for conversation for two of the dependent variables (see Table 3). Those who heard the appearance conversation were lower on both state selfesteem and current feelings of attractiveness than were participants in the roommate conversation condition. We also found a main effect for importance of attractiveness; as importance increased, so did current feelings of attractiveness.

The results pertaining to the Image $\times$ Conversation interaction are of critical importance in testing the social context hypothesis. As expected, a significant Image $\times$ Conversation interaction was found for each of the BES subscales as well as for feelings of attractiveness (see Table 3). We predicted that among women who viewed ideal images, self-evaluations would be lower in the roommate conversation condition than in the appearance conversation condition, whereas among those who viewed neutral images, self-evaluations would be lower in the appearance conversation condition. As can be seen in Table 4, the results support this hypothesis. Simple effects analyses showed that among those who saw ideal images, women who heard the appearance conversation reported more positive feelings of sexual attractiveness $(b=.29, p=.06)$ and physical condition $(b=.46, p<.05)$ than those in the roommate condition; this was not the case for those who saw neutral images. Furthermore, for those who saw neutral images, women who heard the appearance conversation reported lower weight-esteem $(b=-.43, p<.06)$ and feelings of attractiveness $(b=-.94$, $p<.005)$ than those who heard the roommate conversation; this was not the case for those who saw ideal images.

Simple effects analyses also revealed that among those in the roommate conversation condition, women who saw ideal rather than neutral images scored lower on sexual attractiveness $(b=-.28, p<.07)$, weight-esteem $(b=-.53, p<.05)$, physical condition $(b=-.51, p<.002)$, and current feelings of attractiveness $(b=-.94, p<.002)$.
In comparison, in the appearance conversation condition, scores on the BES subscales and feelings of attractiveness were slightly, although not significantly, higher for women who saw ideal images than those who saw neutral images.

It also was hypothesized that participants for whom attractiveness was of high importance would feel less positive about themselves after exposure to ideal rather than neutral images, whereas those low in importance of attractiveness would be less affected by ideal imagery. As expected, significant Image $\times$ Importance of Attractiveness interactions were found for sexual attractiveness, weight-esteem, and feelings of attractiveness. In conducting the simple effects analyses, scores 1 standard deviation below the mean on importance of attractiveness were considered low, and scores 1 standard deviation above the mean were considered high. As can be seen in Table 4, for women high on importance of attractiveness, those who saw ideal images scored lower on sexual attractiveness $(b=-.30, p<.05)$, weight-esteem $(b=-.53$, $p<.05)$, and feelings of attractiveness $(b=-.66, p<.05)$ than those viewing neutral images. In comparison, for those low on importance of attractiveness, there was no difference as a function of image on any of these variables.

Analyses also revealed a significant Conversation $\times$ Importance of Attractiveness interaction for sexual attractiveness $(b=-.25, p<.05)$. For women high on importance of attractiveness, sexual attractiveness ratings were lower in the appearance conversation condition $(M=$ $3.37)$ than in the roommate conversation condition $(M=$ $3.64 ; b=-.26, p<.10)$. In contrast, for those who were low on importance of attractiveness, sexual attractiveness was higher in the appearance conversation condition $(M=3.67)$ than in the roommate condition $(M=3.38 ; b=$ $.27, p<.10)$.

Although there was also a Conversation $\times$ Importance of Attractiveness interaction for state self-esteem, this was qualified by a three-way Image $\times$ Conversation $\times$ Importance of Attractiveness interaction. In the ideal 
TABLE 3: Multiple Regression Analyses: Unstandardized Regression Coefficients for All Dependent Variables

\begin{tabular}{|c|c|c|c|c|c|}
\hline $\begin{array}{l}\text { Independent } \\
\text { Variable }\end{array}$ & $\begin{array}{l}\text { Sexual } \\
\text { Attrac- } \\
\text { tiveness }\end{array}$ & $\begin{array}{l}\text { Weight- } \\
\text { Esteem }\end{array}$ & $\begin{array}{l}\text { Physical } \\
\text { Condition }\end{array}$ & SSES & $\begin{array}{l}\text { Current } \\
\text { Attrac- } \\
\text { tiveness }\end{array}$ \\
\hline \multicolumn{6}{|l|}{ Main effects } \\
\hline Images (I) & -.06 & -.17 & -.16 & -.17 & -.31 \\
\hline Conversation (C) & -.00 & -.09 & .04 & $-.25^{* *}$ & $-.45^{* *}$ \\
\hline $\begin{array}{l}\text { Importance } \\
\text { of attractiveness }\end{array}$ & & & & & \\
\hline (IA) & .00 & .01 & .00 & -.03 & $.09 * *$ \\
\hline$R^{2}$ & .00 & .01 & .01 & $.08 * *$ & $.08^{* *}$ \\
\hline$R^{2}$ & - & - & - & - & - \\
\hline \multicolumn{6}{|l|}{$\begin{array}{l}\text { Two-way } \\
\text { interactions }\end{array}$} \\
\hline $\mathrm{I} \times \mathrm{C}$ & $.49 * *$ & $.79 * *$ & $.75^{* * *}$ & .18 & $1.10^{* * *}$ \\
\hline $\mathrm{I} \times \mathrm{IA}$ & $-.12 * *$ & $-.18 * *$ & -.11 & -.07 & $-.19 * *$ \\
\hline $\mathrm{C} \times \mathrm{IA}$ & $-.11 * *$ & -.13 & -.11 & $-.11 * *$ & .07 \\
\hline$R^{2}$ & .14 & .13 & .13 & .14 & .17 \\
\hline$R^{2}$ & $.14 * * * *$ & $.12 * * *$ & $.12 * * *$ & $.06^{*}$ & $.09 * * *$ \\
\hline \multicolumn{6}{|l|}{$\begin{array}{l}\text { Three-way } \\
\text { interaction }\end{array}$} \\
\hline $\mathrm{I} \times \mathrm{C} \times \mathrm{IA}$ & -.06 & -.08 & -.02 & $-.24 * * *$ & -.13 \\
\hline$R^{2}$ & .14 & .14 & .13 & .19 & .18 \\
\hline$R^{2}$ & .00 & .00 & .00 & $.04^{* *}$ & .00 \\
\hline
\end{tabular}

NOTE: SSES $=$ State Self-Esteem Scale.

$* p<.06 . * * p<.05 . * * * p<.01 . * * * * p<.001$.

image condition, there was a significant Conversation $\times$ Importance of Attractiveness interaction $(b=-.21, p<$ $.01)$, whereas in the neutral image condition, there was no interaction. Subsequent analyses revealed that when presented with ideal images, women high in importance of attractiveness reported lower state self-esteem in the appearance conversation condition than in the roommate conversation condition $(b=-.63, p<.05)$; in contrast, state self-esteem did not vary as a function of conversation for those who were low in importance of attractiveness.

\section{DISCUSSION}

The results of Study 2 replicate the findings of Study 1, providing further evidence that the social context in which ideal images are viewed influences women's subsequent self-evaluations. Among women who viewed ideal images, those who overheard a conversation that focused on physical attractiveness exhibited higher levels of body-esteem than those who overheard a neutral conversation. Findings from this study also highlight the role that individual difference factors can have in influencing the relationship between viewing ideal images and self-evaluations. Women for whom attractiveness was very important expressed lower body-esteem and lower feelings of attractiveness after viewing ideal images. In comparison, women who placed less empha-
TABLE 4: Image $\times$ Conversation and Image $\times$ Importance of Attractiveness Interactions

\begin{tabular}{lccccc}
\hline & \multicolumn{2}{c}{ Conversation } & & \multicolumn{2}{c}{$\begin{array}{c}\text { Importance of } \\
\text { Attractiveness }\end{array}$} \\
\cline { 2 - 3 } \cline { 5 - 6 } Images & & & & \\
\cline { 5 - 6 } Noommate & Appearance & & Low & High \\
Neutral & 3.64 & 3.43 & & 3.37 & 3.68 \\
$\quad$ Sexual attractiveness & 3.20 & 2.77 & & 2.74 & 3.19 \\
$\quad$ Weight-esteem & 3.60 & 3.30 & & 3.30 & 3.57 \\
$\quad$ Physical condition & 3.08 & 2.14 & & 2.19 & 2.97 \\
$\quad$ Current attractiveness & & & & \\
Ideal & 3.36 & 3.65 & & 3.57 & 3.37 \\
$\quad$ Sexual attractiveness & 2.67 & 3.04 & & 2.97 & 2.64 \\
$\quad$ Weight-esteem & 3.09 & 3.55 & & 3.25 & 3.19 \\
$\quad$ Physical condition & 2.19 & 2.35 & & 2.29 & 2.29 \\
$\quad$ Current attractiveness & & &
\end{tabular}

NOTE: Higher values represent more positive self-evaluations.

sis on attractiveness were relatively unaffected by viewing such images.

Importance of attractiveness was a moderating factor for almost all of the dependent measures in this study. Although Cash and his colleagues (1983) found that women are unlikely to engage in social comparison on the dimension of physical attractiveness with women who are fashion models, and therefore dissimilar from themselves, our findings suggest that some women do engage in just this sort of upward social comparison (see also Richins, 1991; Thornton \& Moore, 1993). Despite the fact that the images used in the present study were clearly of models, women who scored high on importance of attractiveness were significantly affected by exposure to these images. Thus, the importance of a particular aspect of the self seems to fuel the social comparison process, making it more likely when a trait is considered important and less likely when it is considered unimportant.

We also found that women who scored high on importance of attractiveness were more vulnerable to the effects of overhearing an appearance-oriented conversation. This conversation was a brief interchange between two women with whom the participant had very little contact, about a third woman that the participant did not know. The two experimenters referred to a mutual friend who had gained weight, let herself go, and become less attractive. They were critical but not overly harsh in their comments. Thus, this was a fairly minor incident and one that was quite removed from the participants. Yet, women who were high on the importance of attractiveness felt markedly worse about themselves after hearing this brief conversation.

Together, these findings suggest that women who see attractiveness as highly important are more vulnerable to the myriad messages that women receive about the 
need to pursue beauty ideals. A substantial body of research suggests that physical attractiveness is an important contingency of self-esteem for women (Crocker \& Wolfe, 1999; see Pliner, Chaiken, \& Flett, 1990). Furthermore, as Crocker and her colleagues (Crocker, 1999; Crocker \& Wolfe, 1999; Sommers \& Crocker, 1999) explain, positive and negative life events that are associated with contingencies of self-esteem may lead to instability of self-esteem, and there is growing evidence that instability of self-esteem, rather than low self-esteem, is a risk factor for depression. Recognizing that contingencies of self-esteem are not exactly the same as the importance placed on a particular attribute, we would nevertheless argue that findings from the current study suggest implications for women's mental health. Given the pervasiveness of appearance-related messages in contemporary society, and given the apparent ease with which some women's body-esteem can be diminished by these messages, our data suggest that the current social environment could result in many women experiencing unstable self-esteem. Women who place a lot of importance on attractiveness, and for whom attractiveness functions as a contingency of self-esteem, may be at increased risk of depression, not because they are consistently unhappy about their bodies but because their body-esteem is unstable.

\section{GENERAL DISCUSSION}

Research examining the effect of ideal images on women's self-perceptions has typically sought evidence of uniform effects of viewing such images. The current studies extend previous research by examining the influence that both social contextual and individual difference factors can have on women's reactions to ideal images. As expected, in both studies, evaluative remarks that reinforced social ideals regarding attractiveness, when paired with ideal images, resulted in more positive self-evaluations. Rather than experiencing further diminished body-esteem, women who experienced doublebarreled messages reported feeling relatively good about themselves.

The current findings suggest that women may process and react to media imagery on a nonconscious level, with the primary evaluative reaction being dissatisfaction with the self. However, events within the social context that increase the likelihood of critical assessment of environmental stimuli seem to circumvent or curtail the negative effects of viewing ideal images. Such results are in line with theory (Bargh, 1990) and research (Bargh \& Pratto, 1986; Higgins \& King, 1981) showing that both trait constructs and behavior can be activated by frequently primed environmental stimuli and that automaticity effects can be undercut by controlled processes (Devine, 1989).
It also may be the case that when faced with stronger or multiple messages regarding social expectations, some individuals are likely to experience psychological reactance (Brehm \& Brehm, 1981). Stronger messages may prime gender-related social norms and expectations regarding physical attractiveness and may elicit resistance on the part of women who experience such messages as constraining. Furthermore, receiving messages from a variety of sources may trigger questions about the fairness of social pressures on women to continually strive for physical attractiveness. It may be that the glossy images in advertising lull women into accepting media-constructed ideals of female beauty, but when reminded of the implications of these ideal images in real life, viewers become critical of these ideal standards. Similarly, images in a magazine may be experienced as a monolithic and distant voice of society and, thus, as relatively objective. Comments made by individuals, on the other hand, may be experienced as relatively subjective and, therefore, as more legitimate targets for criticism. Thus, women who got the double-barreled message may have rejected the messenger and, at the same time, the message. Although these studies have focused on the domain of physical attractiveness, similar processes may occur in the face of other kinds of social messages as well. It is unlikely that the counterpersuasive response found in the present research is isolated only to women's responses to messages regarding attractiveness, and future research could examine how these processes might operate more generally.

In conclusion, we point to several potential areas of future research. First, we need to better understand the process through which women's feelings about their bodies are influenced by social and media messages about attractiveness. Future research should more closely examine the role of automatic and controlled processing and of psychological reactance in producing specific reactions to social messages. Another important area of research would be to examine potential defenses against the negative effects of media images. Clearly, women for whom attractiveness is relatively unimportant are not as affected by such images. Thus, minimizing the importance of attractiveness may provide one avenue of defense, but are there other ways in which women can be inoculated against ideal media images? And, more broadly, how can women learn to defend against the vast array of messages that both convey standards of attractiveness and reinforce the notion that attractiveness is, and should be, of primary importance to women?

There is currently a growing awareness of the objectification of women (Fredrickson \& Roberts, 1997). Perhaps awareness itself acts as a buffer against the effects of the media and social messages regarding appearance. Certainly, feminist critiques of the pres- 
sures on women to concern themselves with physical attractiveness (e.g., Faludi, 1991; Freedman, 1986, 1988; Wolf, 1991) have won widespread readership and have helped raise social awareness of this issue. However, the data presented in these and other studies demonstrate a continuing need to understand how women become vulnerable to such messages and how they might develop adequate defenses. In particular, rather than trying to undo what has already been done, it would be useful to learn how to attenuate the development of this vulnerability in girls (M. Levine, 1999) and to evaluate the success of attempts to dojust that. The current research suggests that presenting women with information that leads them to critically evaluate stereotypic depictions of female attractiveness may be one way to minimize the impact of these types of depictions.

\section{NOTES}

1. All of the images were selected by the authors and six female research assistants. Thirty-one undergraduate women participated in a pilot study in which they rated both the neutral and the ideal images on how they would make women feel about their attractiveness and on the extent to which most women would like each image, using a 9-point scale. Participants rated the neutral images as significantly more likeable $(M=6.36)$ than the ideal images $(M=5.30), t(30)=3.45, p<.005$. They also believed that the ideal images would make women feel significantly more insecure about their attractiveness $(M=4.28)$ than the neutral images $(M=7.00), t(30)=6.57, p<.001$.

2 . To examine the effectiveness of the conversations, 60 undergraduate women participated in a pilot study in which they read a transcript of either the appearance conversation or the roommate conversation. Participants then rated how they felt about the experimenters, how the conversation would make them feel if they overheard it, and how it would make most women feel, each on a scale ranging from 1 (negative) to 7 (positive). Those who read the appearance script felt significantly less positive toward the actual experimenter $(M=4.8)$ than those who read the roommate script $(M=5.6), t(58)=2.52, p<.02$. They also felt less positive toward the confederate experimenter $(M=4.2)$ than did those who read the roommate script $(M=5.3), t(58)=3.23, p<.005$. Women who read the appearance script felt that overhearing the conversation would make them feel significantly more negative $(M=3.4)$ than did women who read the roommate script $(M=5.1), t(58)=5.51$, $p<.001$. They also thought that other women would feel more negative $(M=3.0)$ than did those who read the roommate script $(M=4.9), t(58)=$ $6.25, p<.001$.

\section{REFERENCES}

Adams, G. R., \& Crossman, S. M. (1978). Physical attractiveness: A cultural imperative. Roslyn Heights, NY: Libra.

Bargh, J. A. (1982). Attention and automaticity in the processing of self-relevant information. Journal of Personality and Social Psychology, 43, 425-436.

Bargh, J. A. (1990). Auto-motives: Preconscious determinants of social interaction. In E. T. Higgins \& R. M. Sorrentino (Eds.), Handbook of motivation and cognition: Foundations of social behavior (Vol. 2, pp. 93-130). New York: Guilford.

Bargh, J. A., \& Pietromonaco, P. (1982). Automatic information processing and social perception: The influence of trait information presented outside of conscious awareness on impression formation. Journal of Personality and Social Psychology, 43, 437-449.

Bargh, J. A., \& Pratto, F. (1986). Individual construct accessibility and perceptual selection. Journal of Experimental Social Psychology, 22, 293-311.
Bodenhausen, G. V., \& Macrae, C. N. (1998). Stereotype activation and inhibition. In R. S. Wyer, Jr. (Ed.), Advances in social cognition: Vol. 11. Stereotype activation and inhibition (pp. 1-52). Mahwah, NJ: Lawrence Erlbaum.

Brehm, J. W. (1966). A theory of psychological reactance. New York: Academic Press.

Brehm, S. S., \& Brehm, J. W. (1981). Psychological reactance: A theory of freedom and control. New York: Academic Press.

Brown, J. D., Novick, N. J., Lord, K. A., \& Richards, J. M. (1992). When Gulliver travels: Social context, psychological closeness, and selfappraisals. Journal of Personality and Social Psychology, 62, 717-727.

Buunk, B. P., Collins, R. L., Taylor, S. E., VanYperen, N. W., \& Dakof, G. A. (1990). The affective consequences of social comparison: Either direction has its ups and downs. Journal of Personality and Social Psychology, 59, 1238-1249.

Cash, T. F., Cash, D. W., \& Butters, J. W. (1983). Mirror, mirror, on the wall ... ? Contrast effects and self-evaluations of physical attractiveness. Personality and Social Psychology Bulletin, 9, 351-358.

Collins, R. L. (1996). For better or worse: The impact of upward social comparison on self-evaluations. Psychological Bulletin, 119, 51-69.

Cooley, C. H. (1902). Human nature and the social order. New York: Scribner's.

Crocker, J. (1999, June). Rescuing self-esteem: A contingencies of self-worth perspective. Paper presented at the annual meeting of the American Psychological Society, Denver, CO.

Crocker, J., \& Wolfe, C. (1999). Rescuing self-esteem: A contingencies of worth perspective. Manuscript submitted for publication.

Devine, P. G. (1989). Stereotypes and prejudice: Their automatic and controlled components. Journal of Personality and Social Psychology, $56,5-18$.

Dovidio, J. F., \& Gaertner, S. L. (1993) Stereotypes and evaluative intergroup bias. In D. M. Mackie \& D. L. Hamilton (Eds.), Affect, cognition, and stereotyping: Interactive processes in group perception (pp. 167-193). San Diego, CA: Academic Press.

Faludi, S. (1991). Backlash: The undeclared war against American women. New York: Crown.

Felson, R. B. (1993). The (somewhat) social self: How others affect self-appraisals. In J. Suls (Ed.), Psychological perspectives on the self: The self in social perspective (Vol. 4, pp. 1-26). Hillsdale, NJ: Lawrence Erlbaum.

Franzoi, S., \& Herzog, M. (1986). The body esteem scale: A convergent and discriminant validity study. Journal of Personality Assessment, 50, 24-31.

Franzoi, S., \& Shields, S. (1984). The body esteem scale: Multidimensional structure and sex differences in a college population. Journal of Personality Assessment, 48(2), 173-178.

Fredrickson, B. L., \& Roberts, T. A. (1997). Objectification theory: Toward understanding women's lived experiences and mental health risks. Psychology of Women Quarterly, 21, 173-206.

Freedman, R. J. (1986). Beauty bound. Lexington, MA: D. C. Heath.

Freedman, R. J. (1988). Bodylove: Learning to like our looks and ourselves. New York: Harper \& Row.

Garner, D., Garfinkel, P., Schwartz, D., \& Thompson, M. (1980). Cultural expectations of thinness in women. Psychological Reports, 47 , 483-491.

Geis, F., Brown, V., Jennings, J., \& Porter, N. (1984). TV commercials as achievement scripts for women. Sex Roles, 10, 513-525.

Hansen, C. H., \& Hansen, R. D. (1988). Priming stereotypic appraisal of social interactions: How rock music videos can change what's seen when boy meets girl. Sex Roles, 19, 287-316.

Hardin, C. D., \& Higgins, E. T. (1996). Shared reality: How social verification makes the subjective objective. In R. M. Sorrentino \& E. T. Higgins (Eds.), Handbook of motivation and cognition: The interpersonal context (Vol. 4, pp. 28-84). New York: Guilford.

Heatherton, T. F., \& Polivy, J. (1991). Development and validation of a scale for measuring state self-esteem. Journal of Personality and Social Psychology, 60, 895-910.

Henderson-King, E., \& Henderson-King, D. (1997). The effect of media images on body satisfaction among high and low selfmonitors. Journal of Applied Social Psychology, 27(5), 399-417.

Higgins, E. T., \& King, G. (1981) Accessibility of social constructs: Information processing consequences of individual and contex- 
tual variability. In N. Cantor \& J. F. Kihlstrom (Eds.), Personality, cognition, and social interaction (pp. 69-121). Hillsdale, NJ: Lawrence Erlbaum.

Hinsz, V. B., Tindale, R. S., \& Vollrath, D. A. (1997). The emerging conceptualization of groups as information processors. Psychological Bulletin, 121, 43-64.

Itzin, C. (1986). Media images of women: The social construction of ageism and sexism. In S. Wilkinson (Ed.), Feminist social psychology: Developing theory and practice (pp. 119-134). Philadelphia: Open University Press.

Jennings, J., Geis, F., \& Brown, V. (1980). Influence of television commercials on women's self-confidence and independent judgment. Journal of Personality and Social Psychology, 38, 203-210.

Kenny, D. A., \& Albright, L. (1987). Accuracy in interpersonal perception: A social relations analysis. Psychological Bulletin, 102, 390-402.

Kilbourne, J. (1987). Still killing us softly: Advertising's image of women [Videotape]. Cambridge, MA: Cambridge Documentary Films.

Kimball, M. (1986). Television and sex-role attitudes. In T. M. Williams (Ed.), The impact of television: A natural experiment involving three towns (pp. 303-360). New York: Academic Press.

Levine, J. M., Resnick, L. B., \& Higgins, E. T. (1993). Social foundations of cognition. Annual Review of Psychology, 44, 585-612.

Levine, M. (1999, August). Media literacy in the prevention of disordered eating. Paper presented at the annual convention of the American Psychological Association, Boston.

Markus, H., \& Nurius, P. (1986). Possible selves. American Psychologist, $41,954-969$

McGuire, W. J., \& Padawer-Singer, A. (1976). Trait salience in the spontaneous self-concept. Journal of Personality and Social Psychology, 33, 743-754.

Mead, G. H. (1934). Mind, self and society. Chicago: University of Chicago Press

Myers, P. N., \& Biocca, F. A. (1992). The elastic body image: The effect of television advertising and programming on body image distortions in young women. Journal of Communication, 42, 108-133.

Norman, D. A., \& Shallice, T. (1986). Attention to action: Willed and automatic control of behavior. In R. J. Davidson, G. E. Schwartz, \& D. Shapiro (Eds.), Consciousness and self-regulation: Advances in research and theory (Vol. 4, pp. 1-18). New York: Plenum.

Operario, D., Goodwin, S. A., \& Fiske, S. T. (1998). Power is everywhere: Social control and personal control both operate at stereotype activation, interpretation, and response. In R. S. Wyer, Jr.
(Ed.), Advances in social cognition: Vol. 11. Stereotype activation and inhibition (pp. 163-175). Mahwah, NJ: Lawrence Erlbaum.

Perdue, C. W., Dovidio, J. F., Gurtman, M. B., \& Tyler, R. B. (1990). "Us" and "Them": Social categorization and the process of intergroup bias. Journal of Personality and Social Psychology, 59, 475-486.

Pittman, T. S., \& D'Agostino, P. R. (1985). Motivation and attribution: The effects of control deprivation on subsequent information processing. In J. Harvey \& G. Weary (Eds.), Attribution: Basic issues and applications (pp. 117-141). New York: Academic Press.

Pliner, P., Chaiken, S., \& Flett, G. L. (1990). Gender differences in concern with body weight and physical appearance over the life span. Personality and Social Psychology Bulletin, 16, 263-273.

Richins, M. (1991). Social comparison and the idealized images of advertising. Journal of Consumer Research, 18, 71-82.

Schafer, R. B., \& Keith, P. M. (1985). A causal model approach to the symbolic interactionist view of the self-concept. Journal of Personality and Social Psychology, 48, 963-969.

Silverstein, B., Perdue, L., Peterson, B., \& Kelly, E. (1986). The role of the mass media in promoting a thin standard of bodily attractiveness for women. Sex Roles, 14, 519-532.

Sommers, S., \& Crocker, J. (1999, April). Hopes dashed and dreams fulfilled: Contingencies and stability of self-esteem among graduate school applicants. Paper presented at the annual meeting of the Midwestern Psychological Association, Chicago.

Stice, E., Schupak-Nueberg, E., Shaw, H. E., \& Stein, R. I. (1994). Relation of media exposure to eating disorder symptomatology: An examination of mediating mechanisms. Journal of Abnormal Psychology, 103, 836-840.

Stice, E., \& Shaw, H. E. (1994). Adverse effects of the media portrayed thin-ideal on women and linkages to bulimic symptomatology. Journal of Social and Clinical Psychology, 13, 288-308.

Taylor, S. E., \& Lobel, M. (1989). Social comparison activity under threat: Downward evaluation and upward contacts. Psychological Review, 96, 569-575.

Thornton, D., \& Moore, S. (1993). Physical attractiveness contrast effect: Implications for self-esteem and evaluations of the social self. Personality and Social Psychology Bulletin, 19, 474-480.

Wolf, N. (1991). The beauty myth: How images of beauty are used against women. New York: William Morrow.

Received October 6, 1999

Revision accepted November 7, 2000 